\title{
'|||||||||||||||||||||||||||||||||||||||||||||||||||||||||||||||||||||||.
}

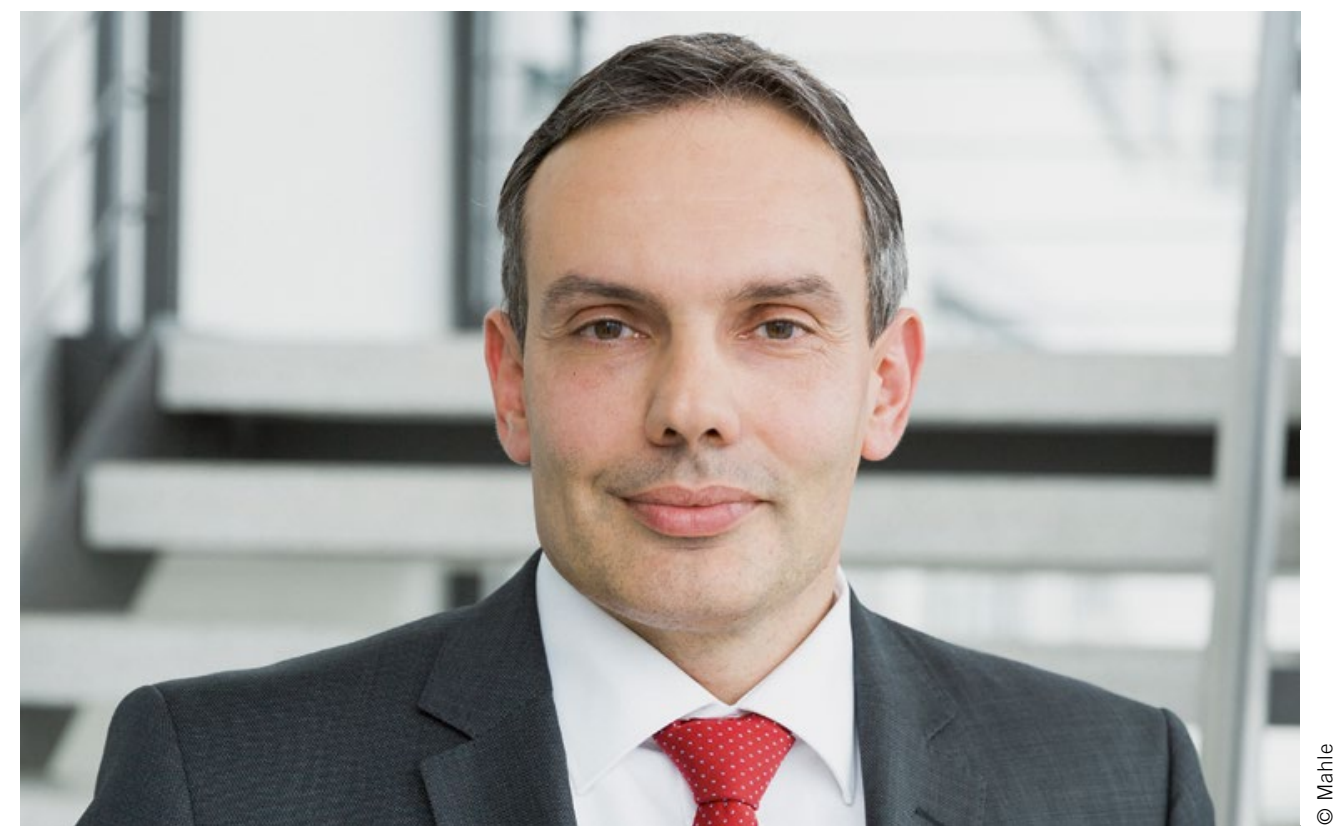

Dr. Martin Berger

Vice President

Corporate Research and

Advanced Engineering der Mahle International $\mathrm{GmbH}$, ATZ-Beirat

\section{Konstanten entlang des Wandels}

In der Evolution sind jene Spezies erfolgreich, die mit sich verändernden Lebensbedingungen besonders gut umgehen können. Bislang wurden diese Veränderungen in der Geschichte unseres Planeten durch natürliche Einflüsse wie Meteoriteneinschläge oder Vulkanausbrüche hervorgerufen. Beim Klimawandel ist die Situation etwas anders, dieser wurde und wird von uns maßgeblich beeinflusst. Die größte Aufgabe unserer Generation ist es, diesen Prozess aufzuhalten. Hier kommt häufig der Begriff der Nachhaltigkeit ins Spiel. Dieser heute inflationär verwendete Ausdruck besteht immer aus drei Hauptkriterien, nämlich dem ökologischen, dem ökonomischen und dem sozialen Aspekt.

In den Wochen des Corona-Lockdowns blieben viele Menschen zu Hause, die Industrieproduktion und der Waren- und Güterverkehr gingen massiv zurück. In vielen Ballungsgebieten verbesserte sich in der Folge die Luftqualität, die sinkende Nachfrage nach Kraftstoffen führte zeitweise gar zu einem negativen Rohölpreis. Den positiven Auswirkungen auf die Umwelt stehen die negativen sozialen und ökonomischen gegenüber. Der Lockdown erfüllte eben nur eines der drei Nachhaltigkeitskriterien. Für den Wiederanlauf beschloss die Bundesregierung ein Konjunkturpaket in bislang nicht dagewesener Höhe, das den Weg der gesamten Wirtschaft in eine nachhaltigere Zukunft ebnen soll. Dass es im Verkehrssektor Elektrofahrzeuge bei einem fossilen Kraftstoffpreis von rund 1 Euro/l kommerziell schwer haben, steht außer Frage. Die Erhöhung der staatlichen Förderung für E-Fahrzeuge ist daher richtig. Auch die ökologisch und ökonomisch sinnvolle Sektorenkopplung lässt sich in Ansätzen in der jüngst beschlossenen nationalen Wasserstoffstrategie erkennen. Grüner Wasserstoff als ein Energieträger der Zukunft kann in Brennstoffzellen und Verbrennungsmotoren direkt genutzt werden und stellt die Basis für synthetische Kraftstoffe dar. Mit letzteren lässt sich die Bestandsflotte von rund einer Milliarde Fahrzeugen weltweit wirkungsvoll in die Herkulesaufgabe Klimaschutz mit einbeziehen. Mit Blick auf die noch zur Verfügung stehende Handlungszeit sollte der regulatorische Rahmen diesbezüglich so überarbeitet werden, dass alle möglichen Hebel zur unmittelbaren Emissionsreduzierung genutzt werden können.

Aus Sicht eines Zulieferers in der Transformation gilt es aktuell umso mehr, die Konstanten entlang des Wandels nicht aus den Augen zu verlieren und seine Kernkompetenzen gezielt für die Entwicklung neuer Produkte zu nutzen. Diese sind entgegen der weitläufigen Meinung häufig nicht an eine bestimmte Antriebsart gekoppelt: Das Thermomanagement etwa ist für ein E-Fahrzeug mindestens so wichtig wie für ein Auto mit Verbrennungsmotor. Kurze Ladezeiten und lange Lebensdauer der Batterie sind hier nur zwei wichtige Faktoren. Die Anforderungen an die Ansaugluftfiltration sind bei einer Brennstoffzelle sogar höher als bei einem modernen Verbrennungsmotor. Notwendige Querschnittsfunktionen wie Lieferantenmanagement, Qualitäts- oder Fertigungskompetenzen lassen sich dagegen auch auf neue Antriebsarten übertragen. Eine Bündelung der Kompetenzen ist notwendig, um Lösungen für den Antrieb von morgen zu entwickeln. Nur so lässt sich im Verkehrssektor und sektorenübergreifend ein wichtiger und nachhaltiger Beitrag zum Klimaschutz leisten. 